\title{
Understanding Pathways to Crime: Can Anomie Theory Explain Higher Crime Rates Among Refugees? - Current Findings from a Swiss Survey
}

\author{
Monika Simmler ${ }^{1,2} \cdot$ Isabelle Plassard $^{3}$. \\ Noëmie Schär ${ }^{3} \cdot$ Maximilian Schuster ${ }^{4}$
}

(C) Springer Science+Business Media B.V. 2017

\begin{abstract}
This study explores the extent to which the comparatively high crime rates among refugees in Switzerland can be explained once anomie theory is employed to take individual and social factors into account. The discrepancy between expectations and internalized goals on the one hand, and accessible legal opportunities on the other, may lead to heightened personal strain and anomic reactions such as innovation and deviance. This research tested this notion via statistical data and a survey of refugees in Switzerland. The results offer moderate support to anomie-centered explanations of crime among refugees.
\end{abstract}

Keywords Anomie theory $\cdot$ Asylum $\cdot$ Deviance $\cdot$ Migration $\cdot$ Refugees

Monika Simmler

monika.simmler@access.uzh.ch

Isabelle Plassard

isabelle.plassard@student.unisg.ch

Noëmie Schär

noemie.schaer@student.unisg.ch

Maximilian Schuster

maximilianjoseph.schuster@student.unisg.ch

1 University of Oxford, Oxford, UK

2 University of Zurich, Zurich, Switzerland

3 Law School, University of St. Gallen, St. Gallen, Switzerland

4 School of Management, University of St. Gallen, St. Gallen, Switzerland 


\section{Introduction}

Statistical data from Switzerland and other European countries suggest that asylum seekers face a disproportionate risk of being identified as offenders (Aebi et al. 2014: 78). Understanding the risk factors associated with the social status of asylum seekers and their involvement in delinquency should now be a high priority, given the rising number of refugees throughout Europe and increasing public concern about crimes committed by immigrants. Considering the sensitivity of the subject, any analysis of crime rates among this population must be undertaken with great care, in order to prevent biased and empty generalizations. The terms "refugee" and "asylum seeker" have many different connotations. The highly variable backgrounds and individual narratives of different refugees should therefore also be examined carefully.

Anomie theory — one of the most influential theories of deviant behavior — offers a promising means of understanding refugees' pathways to deviance, by linking their social position in Western society to their general life circumstances and behaviors. The distance between expectations and actual prospects might explain, at least to some extent, the differences in crime rates among the various segments of the Swiss population. This nexus was examined in this research through the survey presented and analyzed below. Anomie theory, similar to other sociological models, strives to overcome individualistic explanations of different rates of deviant behavior among subgroups of the population (as is the case with theories focusing on pathological personality traits). Instead, anomie theory focuses on the relevance of pressure and its relationship to socially deviant behaviors within certain social and cultural structures (Merton 1938: 672; Merton 1968: 216). Our perspective in this research is sociological; we locate a particularly vulnerable group experiencing strain from social deprivation and evaluate whether that strain leads to a disproportionate rate of deviant activity.

According to the principles of anomie theory and sociological concepts in general, deviant behavior can, like conformist conduct, be seen as a product of social structure (Merton 1938; 672; Merton 1968: 185). Understanding the tensions, contradictions, discrepancies, and strains that accompany such behavior may help researchers to understand deviance and develop strategies to prevent anomie. Moreover, this work should assist in evaluating the value of anomie theory as it pertains to the work of policymakers and therefore complement existing studies using the theory in different context (e.g., Cao 2004; Halpern 2001; Jensen 2002; Karstedt and Farrall 2006). In the following section, certain concepts derived from anomie theory are introduced. Then, the survey of refugees in Switzerland and its methodology, is presented. Next, the official data used to assess refugee involvement in police-recorded crime is discussed. In the final section we provide explanations for refugee offenses using the data collected on migrants' behaviors, their views of the future, and their current life circumstances.

\section{Hypothesizing the Relationship Between Anomie Theory and Refugee Deviance}

\section{The Basic Theoretical Framework of Anomie Theory}

As discussed above, this study's approach is based on the theoretical foundation of anomie theory, one of the most enduring and heavily-researched ideas in criminological research (Maguire et al. 2007: 8). The current study hypothesizes a relationship between 
the main assumptions of this theory and the increased crime rates among refugees. To test this hypothesis, anomie theory had to be translated into certain variables and transformed into a model. Therefore, the basic variations of anomie theory, adopted fundamentals, and definitions of the variables are introduced below.

Referring to a condition of normlessness in society, the term anomie was established by Émile Durkheim (Durkheim 1897) to explain deviance by means of social structure (Kozlova 2015: 80). Durkheim's theory was that anomie, and thus criminality, existed because society had insufficient resources to satisfy all of its members' desires (Farley and Flota 2012: 308). Within the context of anomie, Durkheim addressed questions of personal happiness and fortune, and the premises upon which individuals construct their society (Ortmann 2000: 87); he argued that happiness was not possible if there was an imbalance between needs and the means of their satisfaction (Durkheim 1966: 394). Humans, as compared to animals, have no natural boundaries for their needs (Lamnek 1979: 110). Hence, they tend to live in a permanent state of dissatisfaction that can only be solved by aspiring to limitation and balance with regard to human wants (Ortmann 2000: 97, 102).

Although Durkheim coined the term anomie, it was Robert K. Merton who directed the theoretical focus to the relationship between anomie and deviant behavior. Merton added the essential elaboration that anomie is a socially fostered state of discontent and deregulation that generates crime as part of the routine function of a society by denying universal and equal access to the social means of reaching cultural goals (Merton 1938: 672ff; Merton 1968, 185ff and 215ff; Maguire et al. 2007: 9; Farley and Flota 2012: 308). If those needs and means do not equate and cultural emphasis and social structure drift apart, a "massive, sudden" disruption of balance and anomie will arise and manifest itself as a state of "disorder and normlessness" in society (Lamnek 1979: 108; Ortmann 2000: 99). Once this anomic state emerges, no collective "obligations, expectations and rules" remain to govern the interactions among the various members of society (Lamnek 1979: 110). Deviant behavior, therefore, occurs because of the unsatisfied needs that individuals cannot legitimately meet (Imhof 2010: 42). In that sense, deviant behavior is not based on voluntariness, but rather on constraints blocking the lawful satisfaction of desires (Cloward 1968: 316).

According to Merton (1938 and 1968), society has both social and cultural structures. The cultural structure defines those goals that should be desired by all social participants. It also describes the legitimate means of achieving them (Lamnek 1979: 115). In contrast, the social structure determines the distribution of institutionalized means, and therewith decides whether individuals can realistically and lawfully achieve these culturally appointed goals (Lamnek 1979: 116). Consequently, Merton's theory asserts that the social environment constructed by the cultural structure determines both the goals and the legitimate ways of pursuing them (Ortmann 2000: 78). Indeed, there can be no true equality of opportunity in current society, due to pervasive socio-economic conditions. These conditions inevitably lead to inequalities regarding different positions of origination along the path to achieving these goals (Ortmann 2000: 78).

It is generally assumed that "being successful" is something of great importance to each member of modern society (Ortmann 2000: 77). Even though "success" enjoys a wide variety of definitions, it is usually associated with well-paid work and access to higher education. Kozlova (2015: 140) determined that immigrants — and probably refugees in particular — are remarkably poorly positioned regarding education, job position, and earning capacity. This assumption is supported in Switzerland by official statistics showing that foreigners are much more likely to depend on social welfare than 
are the native Swiss. This is just one of many examples that speak in favor of Merton's argument that some social classes are disadvantaged as a result of the pervasive social structure (Merton 1938 and 1968; Ortmann 2000: 78).

In both presented conceptions of anomie theory, deviance is triggered by a disturbance in the societal equilibrium, and in particular, lower social classes facing a disproportionately high level of pressure to search for illegitimate means of reaching their goals (Baier 2005: 384; Lamnek 1979: 116; Ortmann 2000: 77f). Different responses and adaptions to anomic states include conformity, innovation, ritualism, social retreat, and rebellion (Merton 1938: 676; Merton 1968: 193f; Lamnek 1979: 118). Innovation, as an adaptive behavior, is of particular interest to this investigation. Innovation is characterized as the acceptance of culturally-defined goals that exists alongside a simultaneous rejection of the paths deemed legitimate to achieve these aims (Farley and Flota 2012: 308; Lamnek 1979: 119; Ortmann 2000: 82). Of all the custom modes of response to anomie, this is the one most likely to lead to deviance. More precisely, this reaction type is often associated with a high likelihood of property-related crime (Lamnek 1979: 120; Ortmann 2000: 82).

In its effort to hypothesize a relationship between anomic pressure and offenses committed by refugees in Switzerland, this theoretical foundation has yielded the assumption that refugees arrive in the country with high and often exaggerated hopes; thus, many resort to criminal activity, a behavior attributable to the gap between aspirations and expectations on the one hand and the actual possibilities available on the other hand (Siebert 2008: 19). Indeed, poverty, financial disadvantages, and large differences in the income and wealth distribution have been identified as causing many of the diverse social problems witnessed since the nineteenth century (Killias et al. 2012: 213). Within the context of the current research question, the temptation to simplify the cause of refugee crime rates to financial limitation is strong. However, this approach is too linear and does not deal with the issue's full complexity. As Killias et al. (2012: 213) have suggested, especially with regard to the class system in India, it is not the lack of financial resources so much as the social tension associated with that lack and with the inherent inequalities. Therefore, the focus must not only be on the absence of resources itself, but also on the gap between aspirations to success and actual means of realization (Killias et al. 2012: 214; Kozlova 2015: 81).

Of course, other theories are associated with explaining differences in crime rates among certain populations. Especially in the context of migration and crime, other explanatory variables cannot be ignored and provide further specifications. Although this research focuses on socio-economic factors, other well-known influences shall not be ignored. Therefore, potential biases of the rates as for example by age and gender distribution within the population or differences in the general level of education shall be considered, as these variables are known to significantly impact deviance (Kuhn 2013: 5). Furthermore, there is no doubt that personal narratives are highly influential and have to be taken into account. It has for example been proved that personally experienced violence and witnessing armed conflicts generally make people more violence prone themselves (Couttenier et al. 2017: 1). This so-called "brutalization" is often mentioned — among other variables — in the context of migrants' higher crime rates (Kuhn 2013: 5). These factors are by no means ignored within this study. However, the main aim is to provide a further understanding of the suggestions made by anomie theoretical concepts. Therefore, the focus lies on these social mechanisms and sociological explanations, following the persuasion that these social factors play a major role and are particularly suitable for leading crime policy due to their higher potential changeability. 


\section{Empirical Approach: Combining Societal and Individual Components of Deviance}

The primary aim of this work is to discover how certain social structures exert definite pressure on refugees, and therefore motivate them to engage in unlawful conduct (Merton 1938 and 1968). Following a pure sociological approach, priority is placed on variations in crime rates and not on single incidents. As stated above, anomie is a breakdown in the cultural structure that occurs when there is a disjunction between cultural norms and goals and the socially structured capacity of a group to act in accordance with each (Merton 1968: 216). On a macrolevel, an anomic situation can in fact be understood as subjectively experienced, but it generally describes an objective condition of a social class or group. The question, then, is how the relationship between anomie as a societal condition and individual behavior should be characterized in order to facilitate a greater understanding of its effect (Shoemaker 2010: 127). Merton located the answer to this question in the interaction patterns generated by individuals who collectively live in varying degrees of anomie (Merton 1964; Shoemaker 2010: 127). Merton's notion of strain might be structural, but strain can also be individual. Individual strain refers to the friction and pain experienced by people trying to satisfy their needs within a specific society (Cohen 1997: 59f).

At this point, a distinction should be made between certain subsets of anomie, which include pure micro-theories, pure macro-theories, and theories that combine both individual factors and macro-level variables (Diekmann and Opp 1979: 330). Since Merton, many different variations of anomie theory have been tested. However, it is still debatable whether anomie theory should be considered a matter of the individual or the collective, and thus whether it should be examined from a psychological or sociological perspective (Ortmann 2000: 115). By following Opp's explication of the theory introduced in the upcoming section and testing the described variables therein, this study follows a macro-approach in the sense that it targets statements about an entire population. However, although pursuing a sociological method, this work avoids ignoring socio-psychological mechanisms. Consequently, anomie, as a group condition, can also be linked to and explained by individual lives. However, it is important to note that the following chapters only examine how anomie theory can be used to explain higher crime rates among a specific social group; this work does not suggest that certain individuals are or are more likely to become delinquent.

\section{Methodology}

\section{Research Concept and Defined Variables}

It is an important implication of anomie theory that it is not poverty itself that generates deviant behavior, but poverty surrounded by wealth in a society in which wealth (or at least pursuing wealth) is the norm (Farley and Flota 2012: 308). However, it remains a challenge to obtain data on goals and patterns of access to opportunities. In fact, one of the main challenges to conducting proper empirical research on anomie theory is obtaining data that reflects the combination of high aspirations and minimal opportunity that occurs with varying levels of frequency in different social groups (Merton 1968: 214). To overcome this challenge, the present study has followed the model developed by Karl-Dieter Opp $(1968,1975,1979)$. In this model, the individuals' deviant behavior 
is set as the dependent variable. As social-structural factors for deviance, Opp following Merton — used independent variables falling into the following categories: motivation and potential. Motivation includes the intensity of pursuit of certain aims and the extent to which legitimate and illegitimate norms are internalized. Social-structural potential corresponds on a subjective level with perceived legitimate and illegitimate opportunities that are relevant to the occurrence of deviance (Cloward 1959; Diekmann and Opp 1979: 333). Therefore, in his elaboration of Merton's anomie theory, Opp defined the following five independent variables:

1. As described by Merton (1938 and 1968), the first and most crucial element consists of culturally defined goals, purposes, and interests held out as legitimate objectives for all located members of society. As a measurable independent variable, this can be defined as the intensity of the goals the individual has internalized. This intensity measures the degree to which a person desires the achievement of these culturally defined benchmarks of success (Opp 1968: 113).

2. Also important to the occurrence of deviance is the internalized intensity of legitimate norms, primarily meaning existing societal beliefs regarding the ways certain goals can be legitimately and legally achieved (Merton 1968; Opp 1975). This is essential to understand the degree to which someone wants to realize the legitimate norms prevalent in a particular social and cultural structure.

3. A variable accompanying the rootedness of legitimate norms is the intensity of illegitimate norms (Opp 1975: 78). Acceptance, or even approval, of societally defined illegitimate means and norms has a relevant impact on deviant behavior.

4. Deviance also depends upon the degree of legitimate means and opportunities, meaning the extent to which people believe they can reach their goals following legitimate normalized paths (Opp 1975: 78).

5. The degree of illegitimate means and opportunities is also essential (Opp 1975: 79) to predicting deviance. The existence of illegitimate and legitimate means is not, in and of itself, of high relevance; rather, of importance is the degree to which an individual actually believes in their existence.

The five defined independent variables can be summarized by the following concept, upon which the present research hypothesis is based. The more intense the goals of an individual (1), the less intense the internalized legitimate norms (2), and the higher the intensity of the internalized illegitimate norms (3); and if that coincides with a low degree of access to legitimate potential means and opportunities to reach these goals (4) and a concurrent access to illegitimate potential means and opportunities (5), the more likely the individual is to resort to deviant behavior to fulfill those goals (Opp 1975: 79f).

Following this theoretical basis, this study was conducted by collecting data and testing different items related to each variable. The intent was to measure the extent to which the independent variables prevailed among the surveyed refugees. Instead of gathering personal crime data and linking it with these independent variables, this research attempted to verify the variables' existence in the refugee population and associate them with the official crime data from the same group or class (and not the individual). Therefore, the survey accessed only the independent variables and did not delve into specific deviant behaviors; the assumption was if the later was pursued, a low response rate would be highly likely. 


\section{Refugees: Term and Status}

Before the offenses committed by refugees can be analyzed, it is important to accurately define the term "refugee." According to the Geneva Refugee Convention (UN, 1951) and Swiss law (Article 3 (1) AsylA), refugees are persons "who in their native country or in their country of last residence are subject to serious disadvantages or have a well-founded fear of being exposed to such disadvantages for reasons of race, religion, nationality, membership of a particular social group or due to their political opinions." If these criteria are fulfilled, a person can substantively be deemed a refugee, even if official acceptance is lacking (SEM Asylum Statistics 2016: 5). In the formal sense upon which official statistics rely, a refugee is an immigrant who has been accepted into a country by a formal asylum procedure and, subsequently, been given refugee status (SEM Asylum Statistics 2016: 5). In Switzerland, there are three relevant resident statuses given to refugees. After submitting their asylum application, the status of "asylum seeker" (N) is given; these people are allowed to reside in Switzerland as long as the asylum procedure is pending (SEM Asylum Statistics 2016: 5). The status of "provisionally admitted" (F) is given to people whose asylum claim is not accepted (even if they meet the criteria for refugee status) but for whom an eviction order cannot be executed or is inappropriate (SEM Asylum Statistics 2016: 5). If an asylum claim is definitively accepted, the individual is authorized to receive a "residence permit" (B).

Even though Swiss crime statistics and public debates generally group people with $\mathrm{N}$ and $\mathrm{F}$ statuses together, differentiation is important. Status B individuals cannot be ignored because researchers must consider a very long period of time when analyzing anomic development for these individuals. However, the interviews for this study were conducted only with $\mathrm{N}$ or $\mathrm{F}$ status persons. This was essential for the subsequent proper alignment of independent variables to the dependent variable of deviance.

\section{Data Collection and Participants}

This quantitative study took place in April 2016 and was carried out in three asylum centers in eastern Switzerland. The survey was conducted by means of a paper-based questionnaire translated into six languages: Arabic, English, Farsi, German, Tigrinya, and Urdu. The directors of each asylum center randomly composed the sample $(N=78)$, with an eye to a broad variance in age and country of origin to accurately reflect the asylum population. The participants completed the questionnaire in class or common rooms while observed by the research group. Completion of the questionnaire took approximately 45 min.

Of the 78 participants, $79 \%$ (62) were male and $21 \%$ (16) female. The average age was 26, and in total the ages ranged from 14 to 54 years. This predominantly male and young sample adequately represents the refugee population, but it must already be remembered here that this population group shows a higher level of crime in general. The sample consisted of $53.8 \%$ (42) single and $46.2 \%$ (36) married refugees, with an average of 0.9 children. The countries of origin of the interviewed refugees included: $35.8 \%$ (42) from Afghanistan, $16.7 \%$ (13) from Syria, 9.0\% (7) from Eritrea, 7.7\% (6) from Iran, 3.8\% (3) from Pakistan, 2.6\% (2) from Iraq, $2.6 \%$ (2) from Albania, 2.6\% (2) from Somalia, and 1.3\% (1) from Ghana. Of the total number of refugees interviewed, $84.6 \%$ stated they were Muslim, and $11.5 \%$ Christian. The main reason for their emigration was war $(60.3 \%)$ or political persecution in their respective home countries $(37.2 \%)$. 


\section{Research Design, Data Analysis, and Potential Biases}

The questionnaire contained 83 questions addressing general topics and attitudes, followed by theory-based testing of the five independent variables via the defined items further outlined in the analysis section. Additionally, to complete the analysis of the official data regarding the dependent variable, questions about victimization and observed criminal activity were also included.

Interviewing refugees not only poses challenges with regard to language, which was faced by translating the survey into six different languages, but also with other survey bias. The field of criminological research addresses very sensitive topics and can lead to answering effects of social desirability. These social desirability effects are reasonably believed to be even more prevalent within the researched population of refugees, as they find themselves in an especially difficult social situation during the asylum procedure. This likely effect must be considered when interpreting the collected data, as well as other potential biases. Furthermore, it must be stated that the presented sample was only a snapshot of the refugee population in the spring of 2016; it cannot be seen as representative of refugees around the world or across different time periods, because the composition of the refugee population varies widely over time. Furthermore, a selection bias may have arisen from the use of paper-based surveys; illiterate individuals could not participate and, moreover, a certain educational background was needed for comprehension. This potential bias was considered by simplifying the language as much as possible, in order to maximize the survey participation rate. However, the representativeness of the results presented in this research must be interpreted with caution.

Furthermore, the defined scales and answer schemes did not allow for absolute findings or detailed measurements of goals, norms, and opportunities. With regard to the independent and dependent variables, it was only possible to show tendencies in terms of the explanatory value of anomie theory for a certain population and on a macro-level. Thus, the findings do not allow for reliable statements about individuals. Keeping these concerns in mind, the statistical analysis was conducted by pre-defining the scales of possible answers and, subsequently, calculating the mean value for every item to allow for a comparison of the intensities of different items affecting the examined population. Therefore, tendencies and anomalies could be explored and discussed.

\section{Deviance and Crime Rates Among Refugees}

\section{Asylum Status and Crime Rates in Switzerland: Facts and Figures}

To assess the dependent variable of deviance, a detailed look at official crime and prosecution statistics was necessary, as was an analysis of potential bias effects. This investigation focused on violations of the Swiss Criminal Code (CC) and the Swiss Narcotics Act (NarcA). Special attention was paid to economic crimes and the distributions of different kinds of violations. These official statistics were supplemented by the survey findings concerning deviance and victimization.

As Table 1 shows, $0.58 \%$ of the population in Switzerland can currently be classified as refugees. Regarding the composition of refugees among the permanent population, more than one-third are between 20 and 34 years old (35.60\%; CH: 19.81\%); the range of 25 to 29-year- 
Table 1 Offenders known to the police per 1000 for Criminal Code and drug offenses for Swiss citizens, permanent foreign residents, and asylum seekers (2014)

\begin{tabular}{|c|c|c|c|c|}
\hline Population group & $\begin{array}{l}\text { Absolute } \\
\text { (Relative) }\end{array}$ & $\begin{array}{l}\text { Rate of } \\
\text { offenders } \\
\text { known per } \\
1000 \\
\text { Criminal } \\
\text { Code (total } \\
\text { accusations) }\end{array}$ & $\begin{array}{l}\text { Rate of } \\
\text { offenders } \\
\text { known per } \\
1000 \\
\text { Narcotics Act } \\
\text { (total } \\
\text { accusations) }\end{array}$ & $\begin{array}{l}\text { Rate of offenders } \\
\text { known per } 1000 \text {, } \\
20 \text { to } 24 \text {-year-old } \\
\text { males } \\
\text { Criminal Code } \\
\text { (total accusations) }\end{array}$ \\
\hline Swiss citizens & $6,239,207(75.0 \%)$ & $6.0(37,487)$ & $3.0(18,761)$ & $19.9(3870)$ \\
\hline $\begin{array}{l}\text { Permanent foreign resident } \\
\text { population }(\mathrm{B}, \mathrm{C}, \mathrm{Ci}) \\
\text { excluding asylum population }\end{array}$ & $1,903,911(22.9 \%)$ & $12.4(23,604)$ & $3.8(7213)$ & $33.3(1824)$ \\
\hline Asylum population $(\mathrm{F}, \mathrm{N})$ & $47,994(0.6 \%)$ & $65.2(3127)$ & $26.2(1257)$ & $134.1(574)$ \\
\hline
\end{tabular}

Source: BFS, police crime statistics, own illustration and calculation.

olds is represented most prominently, at $13.32 \%$ (Swiss Federal Statistics Office, 2014). The majority of refugees are male (56.45\%) (Swiss Federal Statistics Office, 2014b).

Additionally, Table 1 offers a view of the relative crime rates per 1000 people and a comparison of the different resident statuses held. These rates originated from the Official Police Crime Statistics and display the annual rates of individuals accused of committing offenses against the $\mathrm{CC}$ and the NarcA. The accusation rates in Switzerland are considerably higher in the asylum population than for the Swiss or permanent residents without Swiss citizenship. In 2014, six out of 1000 Swiss were accused of a violation of the CC (and three of the NarcA); conversely, refugees had a more than tenfold higher rate, with 65.2 accused per 1000 (26.2 regarding the NarcA). As mentioned above, the overrepresentation of young men among refugees could be distorting the validity of this rate. Therefore, the number of accused persons was also calculated only for 20 - to 24 -year-old males. This last column in Table 1 served to relativize the high rate, but still left more than a sextuple increase that cannot be explained by gender or age. In a more detailed examination of the official data (BFS, Police Crime Statistics), these higher rates could also be found in diverse age and sex groups. Even if these demographic characteristics explain a major part of the difference in crime rates, they cannot fully explain higher reporting rates for crimes conducted by immigrants (Papadopoulos 2014).

These higher crime rates among refugees in 2014 (shown in Table 1) can also be seen in other years. Table 2 illustrates the interesting longitudinal development from 2010 to 2014; in the years before 2014, the differences in crime rates between the various population groups were significantly higher. As discussed below, the obvious decrease in crime rates among refugees between 2010 and 2013, and the analyzed year of 2014 (which had a major impact on the crime trends in Switzerland), can be explained by the structure of the refugee population in the past two years. What can be said is that the "wave of refugees" that has recently reached Europe did not - as has been loudly presumed by certain political groups and media - have a negative impact on crime trends, at least not in Switzerland. Crimes committed by refugees are declining, as the absolute and relative numbers for the past two years prove.

According to this analysis of the public data, refugees are clearly overrepresented in Swiss crime statistics, not only compared to Swiss residents, but also to other foreign inhabitants with different residential statuses. This disparity can be partially explained by the overrepresentation of young males among refugees. This fact calls for standardized statistics, which would 
Table 2 Offenders known to the police per 1000 for Criminal Code violations for Swiss citizens, permanent foreign residents, and asylum seekers (2010-2014)

\begin{tabular}{|c|c|c|c|c|c|}
\hline \multirow[t]{2}{*}{ Population group } & \multicolumn{5}{|c|}{ Offenders known per 1000 (Criminal Code) } \\
\hline & 2010 & 2011 & 2012 & 2013 & 2014 \\
\hline Total permanent and non-permanent population & 10.0 & 9.7 & 10.1 & 9.9 & 9.5 \\
\hline Swiss citizens & 6.6 & 6.2 & 6.2 & 6.0 & 6.0 \\
\hline $\begin{array}{l}\text { Permanent foreign resident population }(\mathrm{B}, \mathrm{C}, \mathrm{Ci}) \text {, } \\
(\text { excluding } \mathrm{F}, \mathrm{N})\end{array}$ & 13.9 & 12.9 & 12.9 & 12.7 & 12.4 \\
\hline Asylum population $(\mathrm{F}, \mathrm{N})$ & 99.0 & 111.3 & 140.3 & 110.9 & 68.3 \\
\hline
\end{tabular}

Source: BFS, Police Crime Statistics, own illustration and calculation

include the demographic structure of the respective population (Jann 2013: 105ff). Furthermore, differences exist between distinctive groups of refugees, especially with regard to the country of origin (see Table 3 ).

When analyzing this data, the statistical impact of varying reporting practices for different groups must also be considered. Earlier research has indicated that instances of social control filter deviant behavior; people with specific characteristics are subject to an increased intensity of prosecution (Kubink 1993: 63). Therefore, structural discrimination is a frequent conclusion (Kozlova 2015: 152). Having said this, it is also plausible that foreigners face an increased level of social control. This, in turn, might explain the assumed higher police reporting rates, at least to a certain degree (Kozlova 2015: 152). However, the conclusion of relevant bias caused by reporting practices cannot be supported by the findings of current crime surveys. In fact, the ethnic background of the perpetrator is not the decisive factor determining the willingness of a victim to report a crime (Killias et al. 2012: 157). In addition, many offenses go unreported, so the substantial "dark figure" in official police statistics also biases the results. Moreover, accusation rates do not directly equate to number of convictions.

As an interim conclusion, it can be said that potential biases should certainly not be ignored, but cannot fully account for the considerable differences in accusation rates for refugees and other population groups. For Switzerland, it can be inferred that refugees are more often responsible for crime than are other foreigners who are permanent residents, as well as the

Table 3 Offenders known to the police per 1000, Criminal Code and drug offenses, by country of origin (2014)

\begin{tabular}{lllllll}
\hline Citizenship & $\begin{array}{l}\text { Total } \\
\text { population }\end{array}$ & $\begin{array}{l}\text { Rate of offenders } \\
\text { known per 1000 } \\
\text { Criminal Code }\end{array}$ & $\begin{array}{l}\text { Total } \\
\text { permanent } \\
\text { residents } \\
\text { (without F, N) }\end{array}$ & $\begin{array}{l}\text { Rate of offenders } \\
\text { known per 1000 } \\
\text { Criminal Code }\end{array}$ & $\begin{array}{l}\text { Total } \\
\text { asylum } \\
\text { population } \\
\text { (F, N) }\end{array}$ & $\begin{array}{l}\text { Rate of } \\
\text { offenders } \\
\text { known per 1000 } \\
\text { Criminal Code }\end{array}$ \\
\hline Eritrea & 24,005 & 19.2 & 14,191 & 18.4 & 9793 & 16.1 \\
Syria & 10,029 & 35.9 & 2875 & 17.0 & 7128 & 23.0 \\
Afghanistan & 6957 & 30.8 & 2856 & 18.2 & 4091 & 33.2 \\
Somalia & 7057 & 45.2 & 3153 & 29.2 & 3893 & 47.8 \\
Iraq & 7367 & 44.7 & 5443 & 31.6 & 1902 & 62.6 \\
Iran & 4745 & 35.4 & 3788 & 20.9 & 903 & 53.2 \\
Turkey & 70,452 & 25.7 & 69,199 & 24.0 & 980 & 41.8 \\
Albania & 1646 & 401.6 & 1477 & 27.1 & 79 & 189.9 \\
Nigeria & 2685 & 151.6 & 2207 & 48.5 & 412 & 150.5 \\
Overall & 134,943 & 35.0 & 105,189 & 23.9 & 29,181 & 31.8 \\
\hline
\end{tabular}

Source: BFS, Police Crime Statistics, own illustration and calculation 
Swiss themselves. Table 3 highlights the differences in Swiss accusation rates per country of origin. The nine countries were chosen according to the demographics of those participating in the survey. A certain amount of falsification is to be expected because the official data is only a snapshot; the number of refugees from these countries drastically varies from year to year. Therefore, the accusation rates cannot be taken to show more than general trends. The rates within the total population could moreover be heavily influenced by individuals who neither have asylum status nor any other residential status, but who simply visit Switzerland to commit crimes. Thus, for this research it was important to further group this data into permanent residents and refugees.

Table 3 shows evident differences in crime rates. While Albania and Nigeria had very high rates, the ones from Syria and Eritrea were lower. These differences cannot only be explained by statistical biases, but also by reasons of escape and social and educational circumstances. Additionally, the existing prospects in Switzerland significantly differ according to the asylum seeker's ethnic background. Finally, the possibility of abuse in the context of the asylum procedure must also be considered, as it can have a major impact on the crime rate.

Differences in individual pathways to deviance and the fact that some people engage in criminal activity while others in similar circumstances do not, can be explained by Merton's anomie theory (1938 and 1968) and the concept of relative deprivation. Relative deprivation refers to comparisons that a person makes individually or to their social situation, in relation to associates or others who enjoy a level of respect similar to themselves. This concept can explain why some people in anomic situations do not become criminals to solve their dilemma or - to a large extent - do not even experience the dilemma, even if a structural, objective assessment of the situation would suggest that they should (Shoemaker 2010: 127). In this context, differences in crime rates among different countries of origin can be reduced to the notion that objective dilemmas and social disadvantages are experienced very differently by different individuals in Switzerland, especially because their experiences are influenced by close social groups and peers, and not only by general social strata. Additionally, differences in personal narratives can result in a varying distribution of risk factors. As already pointed out, refugees coming from regions with highly violent conflicts are more likely to be subject to an effect of "brutalization" resulting in a higher violence propensity (Couttenier et al. 2017).

\section{Distribution of Offense Categories}

Figure 1 shows the distribution of crimes committed by refugees, by category. Generally, property offenses are the most frequent violations of the CC. It is of particular note that these crimes are committed by refugees at a rate higher than that seen in other residential groups, and the highest concentrations are found in shoplifting and other theft offenses (BFS, Police Crime Statistics 2015). These findings are consistent with other studies documenting an overrepresentation of refugees in these crime categories (Kozlova 2015: 120ff).

It must again be emphasized that these increased crime rates among refugees are almost certainly biased due to people abusing asylum status for financial enrichment. Criminal tourism and organized crime are phenomena that cannot be underestimated. It is conceivable that asylum status can also be misused to gain entry into Switzerland with the intent to engage in unlawful behavior (Killias et al. 2012: 174). Despite not being refugees in the proper sense, such profiteers are still categorized as refugees in the statistics and have a significant impact on the number of money-related offenses attributable to this category of residential status. These findings, however, can still be brought in line with anomie theory because it is reasonable to 


\section{Relative distribution of offense categories among permanent resident population, 2014}

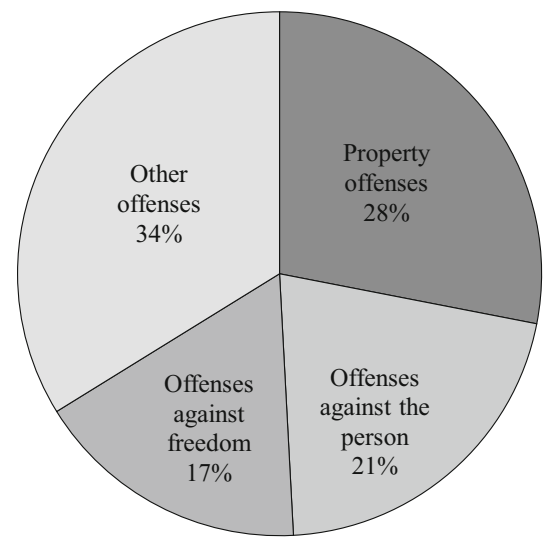

Relative distribution of offense categories among refugee population, 2014

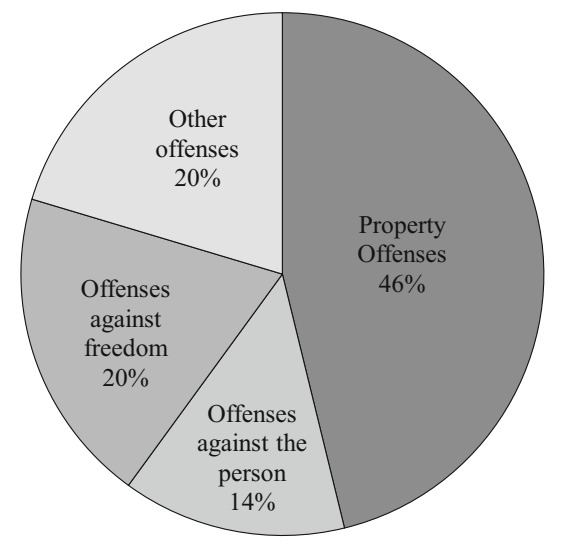

Fig. 1 Nature of Criminal Code offenses in percentage for permanent (Swiss and foreign) residents and asylum seekers (2014). Source: BFS, Police Crime Statistics, own illustration and calculation

assume that at least some of these offenders may have initially been willing to work or otherwise be productive members of society. When lawful opportunities were unavailable, they turned to the criminal as a means of expressing their frustration or due to economic necessity (Shoemaker 2010: 121). In all cases, property offenses can be considered a classic sign of anomic development.

\section{Additional Findings from the Survey}

The dependent variable could not be examined by this survey because researching selfreported delinquency did not seem possible; it was likely to be expected that refugees would not accurately self-report committed crimes, given their situation. Nevertheless, participants were asked several questions about crime and victimization. Of the total sample, $82.8 \%$ stated that they had experienced violence or been the victim of other criminal offenses in their home countries. Furthermore, 19.7\% suffered from physical victimization and 25.8\% from verbal offenses while living in the asylum center. However, $77.1 \%$ still felt "very safe" and $17.1 \%$ "safe" in their asylum center. Of the total surveyed, 5.9\% had experienced an ethnic conflict since arriving in Switzerland. Only five people admitted that they had conflicted with the law. This last finding cannot be regarded as highly significant because the situation in which refugees find themselves is likely to keep them from admitting violations of the law, even when completing an anonymous survey. Therefore, the questionnaire focused on their observations rather than personal experiences. The findings are discussed in detail, below.

After analyzing the data regarding deviant behavior among refugees as the independent variable, it was concluded that there was definitely a higher level of deviance and crime among this population than in other residence groups. Below, this conclusion is examined with regard to the extent to which certain independent variables, as hypothesized by Opp and Merton, can be used to explain this finding. 


\section{Research Findings: The Dependent Variables}

\section{Intensity of Goals}

The extent to which the interviewed group internalized social and cultural goals, as well as the intensity of those goals, was analyzed via 12 items. The results, presented in the following graph, show that such goals were to a strong degree internalized. Not only were work and education-related goals highly prevalent, but also traditional wealth aims like having the opportunity to buy a car or go on vacation. Therefore, it can be inferred that the participants shared cultural objectives similar to those prominent in Swiss and other Western societies, and actively sought to attain them. In addition to the specific research findings, it can also be concluded that refugees shared certain well-known general goals and values predominant in Western society, where monetary success, status symbols, and consumer goods are avidly pursued (Neubacher 2014: 94). In a consumption-oriented society, property and consumption are emphasized as desirable for all (Rebmann 1998: 287). Thus, it is highly plausible and supported by the findings of this research that refugees adapt to those values and goals and strive to achieve them (Fig. 2).

\section{Intensity of Legitimate Norms}

The second variable was tested via five items, focusing on the available legitimate norms and intensity with which they were internalized by the refugees. The results concerning the general principles and norms accepted by society did not come as a surprise. Refugees understood that the law was important, agreed with core values, and respected the equality of all human beings. Therefore, a high degree of intensity was found with regard to legitimate norms. There were no signs of a lack of legitimate norms, even though the results may have been biased by respondents hoping to answer in accordance with society's desire (Fig. 3).

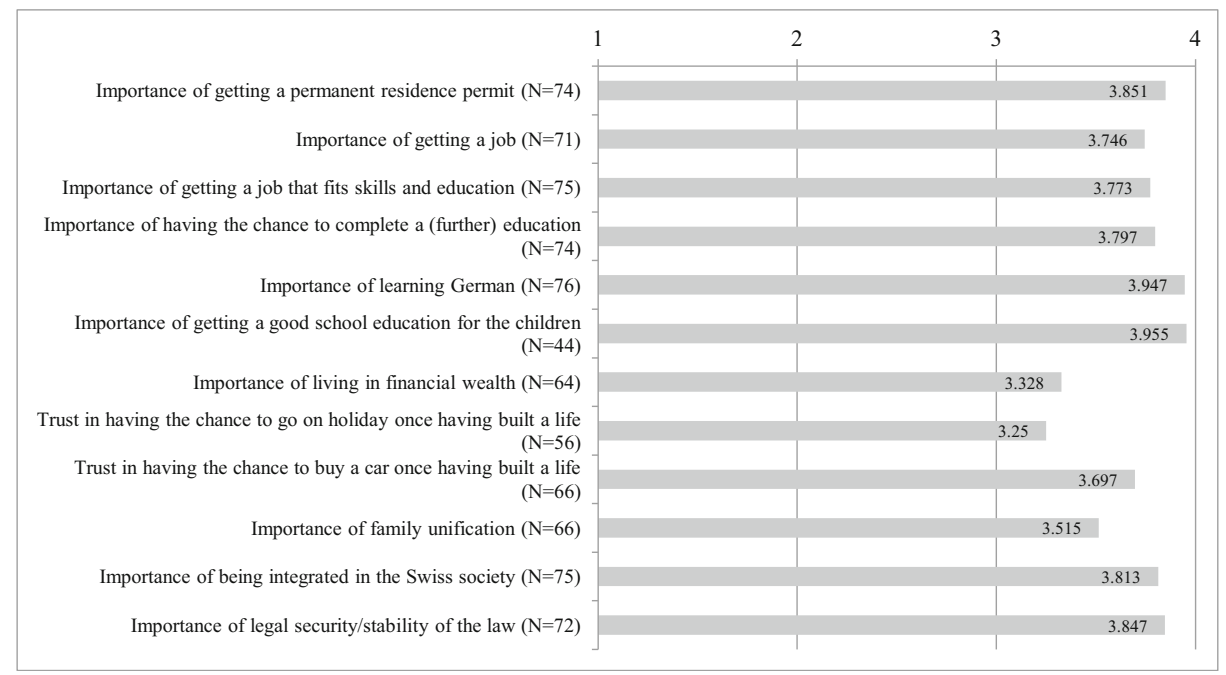

Fig. 2 Importance of several goals among interviewed asylum seekers (average scores; 1 = not important, 4 = very important). Source: Survey, own illustration and calculation 
M. Simmler et al.

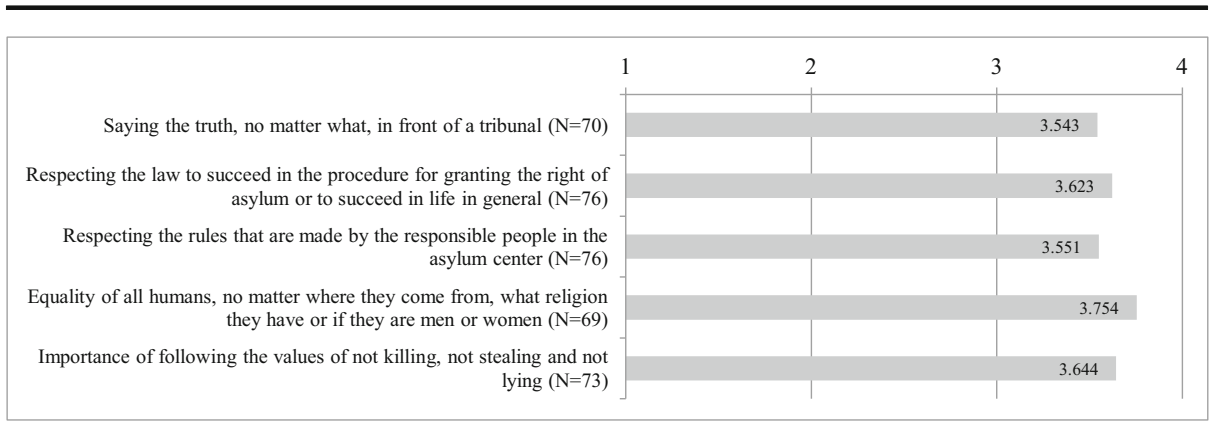

Fig. 3 Compliance with legitimate norms among interviewed asylum seekers (average scores; $1=$ does not accept at all, 4 = fully accepts). Source: Survey, own illustration and calculation

\section{Intensity of Illegitimate Norms}

As the following graph illustrates, six additional items referring to the intensity of illegitimate norms were tested. The results reflect the negative side of the previously mentioned variables and present a more complicated result. Only a few participants believed that it was worthwhile to break the law to find success in life. However, there was some skepticism regarding the Swiss legal framework, if only to a small extent. The levels of willingness to do anything to help their families and to repay the cost of their escape were not particularly intense, even though debt repayment generally seemed to constitute a significant concern. Of the participants, $47.4 \%$ answered that they had incurred debt attributable to their escape to Switzerland. This suggests a high risk of financial pressure and social strain in the coming years that could present difficulties, especially keeping in mind the usual financial constraints faced by refugees in their destination countries. Nevertheless, the results of the self-assessments did not indicate that refugees — at least at this point in the asylum procedure - had more intense desires to pursue illegitimate norms than did other residence groups (Fig. 4).

\section{Degree of Legitimate Means and Opportunities}

The survey included nine items to test the existence and degree of legitimate options and opportunities. The refugees were asked what they assumed their opportunities and prospects to be, at present and in the future. In sum, those surveyed were very optimistic. Most believed

\begin{tabular}{|c|c|c|c|c|}
\hline & 1 & 2 & 3 & 4 \\
\hline $\begin{array}{l}\text { Believe that it can pay off in certain situations to break the law to } \\
\text { succeed in life }(\mathrm{N}=67)\end{array}$ & 1.836 & & & \\
\hline $\begin{array}{l}\text { Believe that rules and laws in Switzerland are made in a way, which will } \\
\text { limit personal freedom and hinders individual happiness }(\mathrm{N}=56)\end{array}$ & & 2.536 & & \\
\hline $\begin{array}{l}\text { Belive in fundamental gender differences which ask for different roles } \\
\text { and duties in society ( } \mathrm{N}=62)\end{array}$ & & 2.536 & & \\
\hline $\begin{array}{l}\text { Willingness to do everything - allowed or not - to help the family } \\
\qquad(\mathrm{N}=64)\end{array}$ & & 2.437 & & \\
\hline $\begin{array}{l}\text { Willingness to do everything - allowed or not - to pay back the costs of } \\
\text { escape }(\mathrm{N}=58)\end{array}$ & 1.793 & & & \\
\hline $\begin{array}{l}\text { Willingness in the personal environment to break the law to help } \\
\text { yourself out of financial problems }(\mathrm{N}=66)\end{array}$ & 1.292 & & & \\
\hline
\end{tabular}

Fig. 4 Acceptance of rule breaking among interviewed asylum seekers (average scores; $1=$ does not accept at all, 4 = fully accepts). Source: Survey, own illustration and calculation 
that they would soon find a job corresponding to their skill level. Furthermore, they seemed hopeful that they would have the chance to become fully integrated into Swiss society after completing the asylum procedure. Regarding their current situation, the results were more complicated. While educational opportunities seemed to be a satisfactory solution at the moment, the financial environment was not only inadequate but unsatisfying. Additionally, neither their contact with Swiss inhabitants nor the support offered by third parties appeared to be ideal, even though either could lead to successful integration. Nevertheless, it needs to be pointed out that the availability of legitimate options and opportunities was stressed as highly valued and promising. Hence, this self-estimation is particularly interesting because the statistics regarding actual prospects contrast with these self-reported results. The gap between the refugees' estimated chances and actual achievement will likely be grounds for disappointment, strain, and eventual anomic reaction (Fig. 5).

Refugees' financial means tend to be seriously limited. According to public social welfare statistics, the rate of persons depending on social welfare is $65 \%$ higher among foreigners than Swiss citizens (BFS, Social Welfare Statistic in Asylum Matters 2014). In Switzerland, most refugees are indeed supported by social welfare. However, the social welfare benefits are $20 \%$ lower than what Swiss applicants receive. This amounts to approximately CHF 1150 per person, per month (BFS, Social Welfare Statistic in Asylum Matters 2014). In comparison to the 2014 average monthly income of CHF 6536 per person in Switzerland (BFS, Social Welfare Statistic in Asylum Matters 2014), this denotes a seriously poor financial situation for refugees. Not only is the current state of affairs suboptimal, but refugees are also less likely to become independent from social welfare in the future. For instance, refugees are not allowed to work at all during the first three months after submitting their asylum application (Art. 43, Abs. 1, AsylA) and after the three-month ban, they face hindered access to the job market for various reasons such as language barriers (Kubink 1993: 73; Siebert 2008: 19).

At the end of 2015 , only $30 \%$ of the provisionally admitted refugees in Switzerland were employed. Out of those who had been formally accepted for residency, only $21 \%$ were employed (SEM Asylum Statistics 2016). These numbers reflect both their short and longterm realities. Even after ten years, only $48 \%$ of former refugees could find a job (SEM Asylum Statistics 2016). Therefore, it is highly likely that a large majority of the refugees interviewed for this research will depend upon social welfare indefinitely. According to current

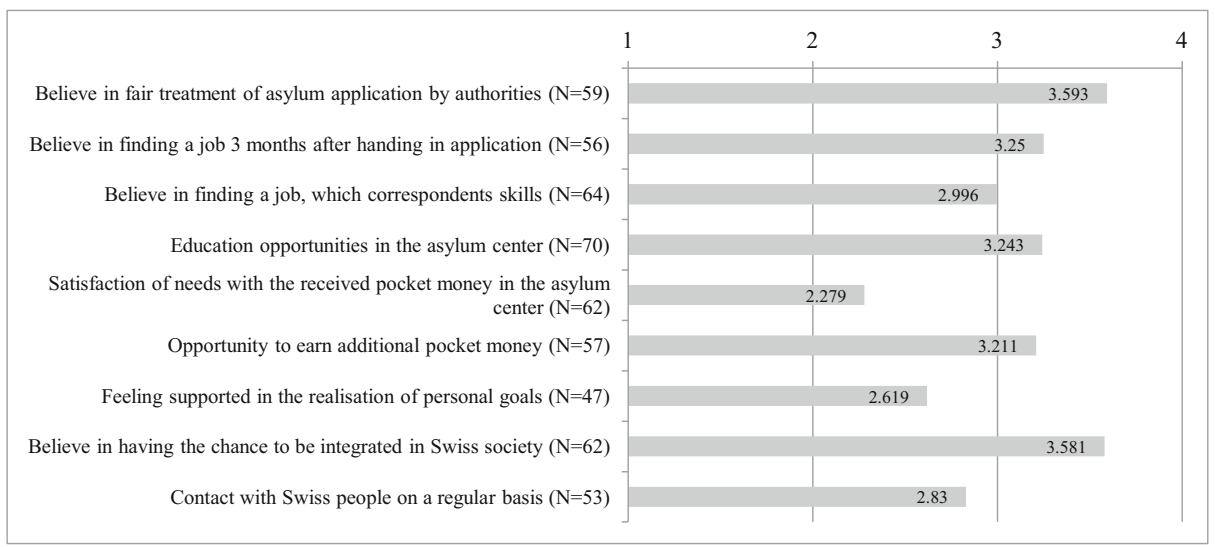

Fig. 5 Perceived legitimate opportunities among interviewed asylum seekers (average scores; $1=$ does not accept at all, 4 = fully accepts) Source: Survey, own illustration and calculation 
calculations, $80 \%$ of such immigrants will need financial support for at least the first five to seven years that they spend in their host country (SKOS, Swiss Conference for Social Welfare Factsheet 2016). These statistics support the previously mentioned assumption that refugees are generally overly optimistic, at least in terms of the degree of legitimate economic opportunities available to them. The gap between hopes, goals, and reality serves as a basis for disappointment and can ultimately lead to deviant behavior, a trajectory suggested by anomie theory. Therefore, it is not surprising that refugee groups display a tendency toward a higher rate of crime, and are especially prone to commit property crimes.

\section{Degree of Illegitimate Means and Opportunities}

As a fifth independent variable, this research examined the degree to which refugees could take advantage of illegitimate means and opportunities in their daily lives, despite being aware that these actions are considered unacceptable by Swiss society. Refugees' perceptions regarding surveillance and control of their behavior were researched with items 1 and 7 of the figure below. It was essential to determine whether they understood that breaking social rules or established law could lead to drastic consequences. The questions were posed such that the refugees were only asked about their observations and rumors of which they were aware, instead of their own direct experiences. While the majority did not report any direct temptations or observations, $17.9 \%$ of the respondents stated that they had heard about the possibility of illegally influencing the asylum procedure, and $24.4 \%$ of the individuals admitted that they had already observed such a behavior. Another $2.6 \%$ reported that they had themselves been offered illegal opportunities in Switzerland. In general, the number of refugees who left this kind of question blank or answered with "do not know" was striking. These findings can be interpreted in two ways: they either felt uncomfortable giving an answer or they had trouble understanding the question. To conclude, it is undeniably difficult to assess the degree of illegitimate means and opportunities available to persons seeking asylum, as they are kept under continuous observation and have a substantial incentive to be discrete. Even after being granted asylum, self-reported data related to illegitimate means of economic gain are difficult to assess. It is probable that once leaving the asylum center and moving to a regular apartment,

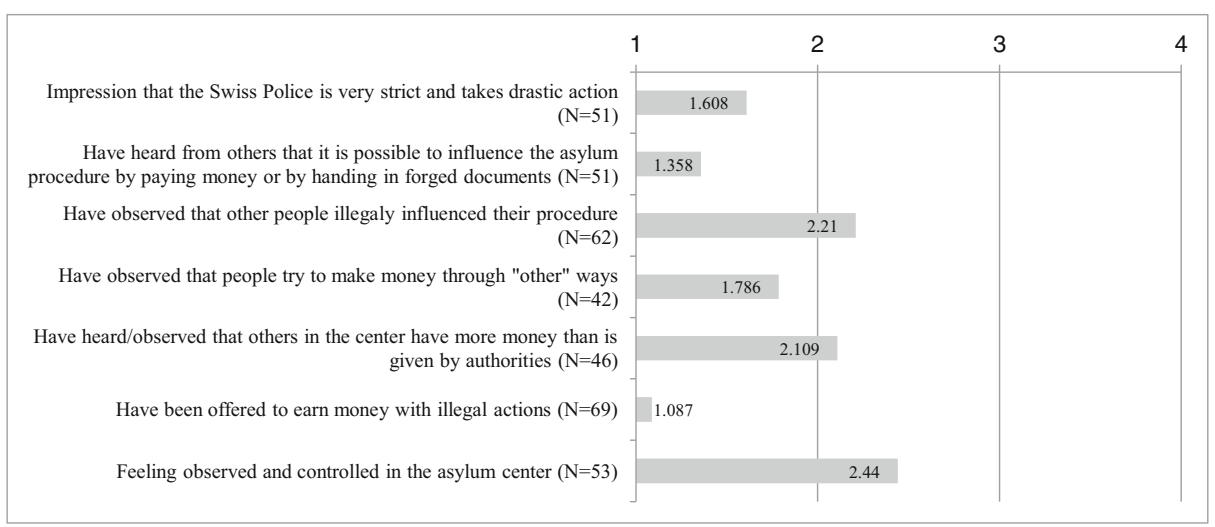

Fig. 6 Perceived illegitimate means and opportunities among interviewed asylum seekers (average scores; $1=$ does not accept at all, $4=$ fully accepts). Source: Survey, own illustration and calculation 


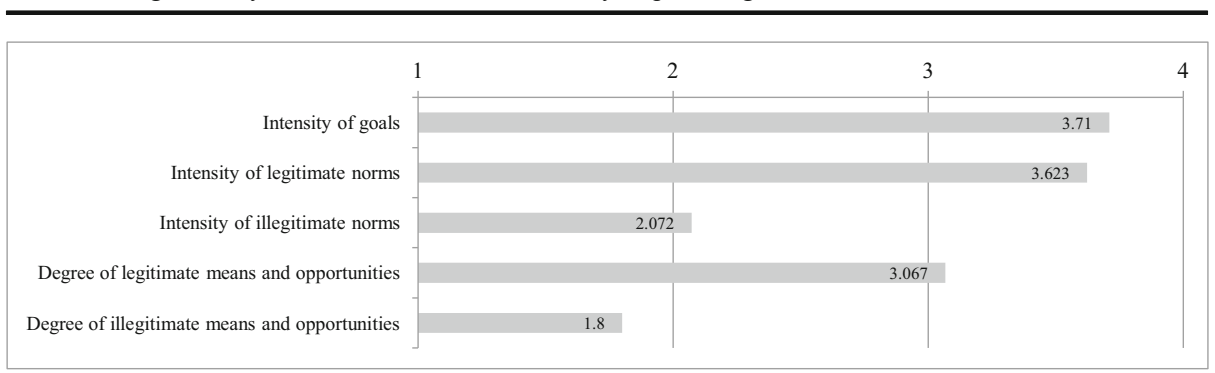

Fig. 7 Results: overview of independent variables. Source: Survey, own illustration and calculation

such individuals would have at least the same types of opportunities to break the law as every other citizen in Switzerland (Fig. 6).

\section{Overview: Independent Variables}

Examining anomie theory in the current study afforded the opportunity to test the five independent variables and contextualize them with deviance as a dependent variable. In the methodology section, it was discussed how anomie increases as the intensity of goals as the prevalence of illegitimate norms and opportunities grows and the number of legitimate norms and options declines (Opp 1975: 79f). In summary, the previously presented findings suggest that there is a high intensity of cultural and social goals among refugees. These findings coincide with the self-estimated high degree of legitimate means and opportunities believed to be available, and indicate that at least initially they feel optimistic about their prospects. However, public statistics reveal a gap between refugees' self-estimation and the reality in Switzerland, especially with regard to their future opportunities. This gap could generate disappointment and frustration. The lack of opportunities, in combination with high hopes and goals, could potentially encourage deviant behavior. Therefore, a low intensity of illegitimate norms and a low stated degree of illegitimate behavior, together with a high intensity of legitimate norms, seems to indicate that at this stage in the asylum procedure, shortly after initial immigration, these variables of anomie theory could not be determined. However, the findings still offer great possibilities and include indications that an anomic state could potentially be discovered in this population, later in a few years (once former refugees notice the absence of legitimate prospects and realize that they cannot reach their goals as initially anticipated). Indeed, the determined gap between the refugees' expectations and the existing opportunities shown by official data can result in anomie and can likely serve as a ground for deviant behavior (Fig. 7).

\section{Discussion and Conclusion}

As the findings of the survey show, higher crime rates among refugees cannot be explained by their lack of good intentions or lower intensity of legitimate norms. Quite the contrary, the results obtained in this study suggest a different explanatory variable: the potentially strong contrast between socially defined cultural (material) goals on the one hand and unevenly distributed existing means and prospects on the other. This gap creates socio-culturally determined peer pressure to which all in society are exposed, and which ultimately forces individuals to adapt in order to reach their socially defined (and therefore internalized) goals 
(Neubacher 2014: 95). This reaction to an anomic situation can be characterized as an adaptation mode of innovation, which is usually accompanied by the high possibility of deviant behavior. Thus, it offers a plausible explanation for the high crime rate among refugees.

In this context, the offenses committed by refugees can also be qualified as "innovations," as refugees try to resolve the discrepancy between social goals and lawful and legitimate opportunities by adopting "innovative" or alternative measures. The less likely refugees are to achieve their goals by lawful conduct, the more likely they will be to circumvent legitimate norms (Kunz 2011: 96).

These results highlight the importance of addressing this problem; the data clearly indicate that the refugees interviewed had a strong desire to be integrated, obtain gainful employment, and adhere to legitimate measures, at least initially. The intensity of their belief in legitimate norms and values was high. In other words, it seems likely that even if the general situation leads to disappointment due to a lack of legitimate means, the majority will never engage in criminal activity. Rather, the intensity of their legitimate norms will prevent an anomic reaction, even if the remaining four variables are predominant. Hence, time must be invested in developing actual legitimate opportunities. This is a key precondition not only to avoiding personal disappointment, but also to preventing demoralization and, ultimately, the dissolution of legitimate norms.

It is also clear from the evidence collected that anomie theory offers a plausible sociological explanation for the differences among social classes with regard to rate of deviance, and the socio-political implications are easy to see (Farley and Flota 2012: 311). When refugees strive for prosperity in areas where legitimate opportunities remain unavailable, they will continue to have a high likelihood of deviant behavior. In any case, increasing economic inequality should give society cause for concern, as equal opportunity to acquire wealth is a desirable goal (Farley and Flota 2012: 311; Merton 1968: 188). Consequently, society should strive to close the gap between goals and means, and limit the potential disappearance of socially desirable norms. The finding supports general claims that fostering perspectives for labor market integration and developing further general job and education prospects will be able to lower the pressure experienced and to avoid anomic strains (see Couttenier et al. 2017: 2f). Therefore, extending the legitimate means is crucial in this regard.

Merton's (1968: 188) central hypothesis, that deviant behavior can be regarded as a symptom of dissociation between culturally prescribed aspirations and socially structured avenues for realizing them, was supported by this study. The findings speak to an explanation in line with anomie theory. Consequently, the following two main conclusions can be drawn. First, it is evident that the reason for higher crime rates among refugees is not ethnical differences, human error, or an absence of values, legitimate norms, or motivation. Rather, most refugees aim to secure their existence to the greatest extent possible, even in the face of serious obstacles. This is normal behavior, and generally refugees do not commit criminal offenses, even when in dire financial circumstances. Second, anomie theory can improve the overall understanding of the primary cause of criminal activity among different social classes, and this understanding will help society develop prevention policies and reduce crime rates. If different social pressures among specific social classes can explain crime rates, changing the opportunity structure is a promising way to positively influence criminality. By reducing the above-mentioned pressure, it is highly likely that corresponding changes in crime rates will occur (Merton 1968: 246). 


\section{References}

Aebi, M. F., et al. (2014). European sourcebook of crime and criminal justice statistics (5th ed.). Helsinki: European Institute for Crime Prevention and Control.

Baier, D. (2005). Abweichendes Verhalten im Jugendalter. Ein empirischer Vergleich verschiedener Erklärungsansätze. Zeitschrift für Soziologie der Erziehung und Sozialisation, 4, 381-398.

BFS, Swiss Federal Statistical Office (2014a). Social Welfare Statistic in Asylum Matters.

BFS, Swiss Federal Statistical Office (2014b-2016). Police Crime Statistics.

Cao, L. (2004). Is American society more anomic? A test of Merton's theory with cross-National Data. International Journal of Comparative and Applied Criminal Justice, 28, 15-32.

Cloward, R. A. (1959). Illegitimate means, anomie and deviant behaviour. American Sociological Review, 24, $164-176$.

Cloward, R. A. (1968). Illegitime Mittel, Anomie und abweichendes Verhalten. In F. Sack \& R. König (Eds.), Kriminalsoziologie (pp. 314-338). Frankfurt am Main: Akademische Verlagsgesellschaft.

Cohen, A. K. (1997). An elaboration of anomie theory. In N. Passas \& R. Agnew (Eds.), The future of anomie theory (pp. 52-61). Boston: Northeastern University Press.

Couttenier, M, Preotu, V., Rohner, D. and Thoenig M. (2017). The violent legacy of victimization: post-conflict evidence on asylum seekers, crimes and public policy in Switzerland. CEPR Working Paper, DP11079.

Diekmann, A., \& Opp, K.-D. (1979). Anomie und Prozesse der Kriminalitätsentwicklung im sozialen Kontext. Vorschläge für die Weiterentwicklung und Formalisierung der Anomietheorie. Zeitschrift für Soziologie, 8, $330-343$

Durkheim, E. (1897). New York: The Free Press.

Durkheim, E. (1966). Über die Anomie. In: Wright Mills C (Ed.), Klassik der Soziologie (pp. 394 436). Frankfurt am Main: S. Fischer.

Farley, J. E., \& Flota, M. W. (2012). Sociology (6th ed.). London: Paradigm.

Halpern, D. (2001). Moral values, social trust and inequality: Can values explain crime? British Journal of Criminology, 41, 236-251.

Imhof, R. (2010) Determinanten kriminellen Verhaltens. Empirische Überprüfung eines erweiterten Rational Choice-Modells. PhD Dissertation, University of Bern.

Jann, B. (2013). Herkunft und Kriminalität. Ergebnisse der polizeilichen Kriminalstatistik. In D. Fink, A. Kuhn, \& C. Schwarzenegger (Eds.), Migration, Kriminalität und Strafrecht. Fakten und Fiktion (pp. 101-116). Stämpfli Verlag: Bern.

Jensen, G. (2002). Institutional anomie and societal variations in crime: A critical appraisal. International Journal of Sociology and Social Policy, 22, 45-74.

Karstedt, S., \& Farrall, S. (2006). The moral economy of everyday crime: Markets, consumers and citizens. British Journal of Criminology, 46, 1011-1036.

Killias, M., Kuhn, A., \& Aebi, M. F. (2012). Précis de criminologie (3rd ed.). Berne: Stämpfli Editions SA.

Kozlova, A. (2015). Ausländerkriminalität in der Schweiz. Zusammenhang zwischen Migration und Kriminalitätsentwicklung. $\mathrm{PhD}$ Thesis, University of Bern.

Kubink, M. (1993). Verständnis und Bedeutung von Ausländerkriminalität. Eine Analyse der Konstitution sozialer Probleme. Pfaffenweiler: Centaurus Verlag.

Kuhn, A. (2013). Comment s'explique la surreprésentation des étrangers dans la criminalité? Vivre Ensemble, Hors-Série 1. Marsyas, 2013, 1-6.

Kunz, K. L. (2011). Kriminologie (6th ed.). Bern: Haupt.

Lamnek, S. (1979). Theorien abweichenden Verhaltens. Eine Einführung für Soziologen, Psychologen, Pädagogen, Juristen, Politologen, Kommunikationswissenschaftler und Sozialarbeiter. München: W. Fink.

Maguire, M., Morgan, R., \& Reiner, R. (2007). The Oxford handbook of criminology. Oxford/New York: Oxford University Press.

Merton, R. K. (1938). Social structure and anomie. American Sociological Review, 3, 672-682.

Merton, R. K. (1968). Social theory and social structure. New York: Free Press.

Merton, R.K. (1964). Anomie, anomia, and social interaction. Contexts of deviant behaviour. In: Clinard, M.B. (Ed.), Anomie and deviant behavior. A discussion and critique (pp. 213-244). New York: Free Press.

Neubacher, F. (2014). Kriminologie (2nd ed.). Baden-Baden: Nomos.

Opp, K.-D. (1968). Kriminalität und Gesellschaftsstruktur. Eine kritische Analyse soziologischer Theorien abweichenden Verhaltens. Neuwied/Berlin: Hermann Luchterhand Verlag.

Opp, K.-D. (1975). Soziologie der Wirtschaftskriminalität. München: Verlag C.H. Beck.

Ortmann, R. (2000). Abweichendes Verhalten und Anomie. Entwicklung und Veränderung abweichenden Verhaltens im Kontext der Anomietheorien von Durkheim und Merton. Freiburg im Breisgau: Ed. iuscrim, Max-Planck-Institut für Ausländisches und Internationales Strafrecht. 
Papadopoulos, G. (2014). Immigration status and property crime: An application of estimators for underreported outcomes. IZA Journal of Migration, 3, 12-42.

Rebmann, M. (1998). Ausländerkriminalität in der Bundesrepublik Deutschland. Eine Analyse der polizeilich registrierten Kriminalität von 1986-1995. Freiburg im Breisgau: Ed. iuscrim, Max-Planck-Institut für Ausländisches und Internationales Strafrecht.

SEM, Swiss State Secretariat for Migration (2016). Asylum Statistics.

Shoemaker, D. J. (2010). Theories of delinquency. An examination of explanations of delinquent behavior (6th ed.). Oxford/New York: Oxford University Press.

SKOS, Swiss conference for social welfare (2016). Factsheet.

Siebert, I. (2008). Kriminelle Ausländer. Mythos oder Realität? Frankfurt: Verlag für Polizeiwissenschaft. 